\title{
Konsep Marketing Berbasis Maqoshid Al-syari'i Imam Al-Ghazali
}

\author{
Ivan Rahmat Santoso
}

Fakultas Ekonomi, Universitas Negeri Gorontalo, Indonesia

*Email korenpondensi: ivanrahmatsantoso@gmail.com

Abstract

Imam Al-Ghazali's views on socioeconomics stem from a concept called the "function of Islamic social welfare". The mind that forms the basis of his work is the benefit of the common good contained in the sharia maqasid. This study aims to formulate the concept of marketing based on the values of the Maqasid Shariah mashlahat. This research method is a descriptive qualitative approach to the study of literature. The results of the study found that marketers' marketing planning must pay attention to the concept of maslahah as the goal of Islamic maqasid and guidance in marketing strategies. In addition to achieving the goals maslahah a marketer needs to implement a drive market strategy as an effort to direct consumers to prioritize the need for good rather than desires that lead to actions that exceed the limits.

Keywords: Marketing, Maqashid Syariah, Maslahah

\begin{abstract}
Abstrak
Pandangan Imam Al-Ghazali mengenai sosioekonomi bersumber dari suatu konsep yang disebut sebagai "fungsi kesejahteraan sosial Islami". Pokok pikiran yang menjadi landasan karyanya adalah maslahat berupa kebaikan bersama yang terkandung dalam maqasid syariah. Studi ini bertujuan untuk merumuskan konsep marketing yang berlandaskan nilai-nilai mashlahat maqasid syariah. Metode penelitian ini adalah kualitatif desktiptif dengan pendekatan studi kepustakaan. Hasil penelitian menemukan bahwa perencanaan pemasaran marketer harus memperhatikan konsep maslahah sebagai tujuan dari maqasid syariah dan panduan dalam strategi pemasaran. Selain itu untuk mencapai tujuan maslahah seorang marketer perlu menerapkan strategi drive market sebagai upaya mengarahkan konsumen dalam memprioritaskan kebutuhan untuk kebaikan dibanding keinginan yang membawa kepada tindakan yang melampaui batas.
\end{abstract}

Kata kunci: Marketing, Maqashid Syariah, Maslahah

Saran sitasi: Santosa, I. (2019). Konsep Marketing Berbasis Maqoshid Al-syari'i Imam Al-Ghazali. Jurnal Ilmiah Ekonomi Islam, 5(03), 147-165. doi: http://dx.doi.org/10.29040/jiei.v5i3.557

DOI: http://dx.doi.org/10.29040/jiei.v5i3.557

\section{Pendahuluan}

Pemasaran (marketing) dalam perkembangannya selalu menjadi ujung tombak keberhasilan suatu bisnis, walaupun dari masa ke masa, seiring itu juga terjadi pergeseran paradigma perilaku konsumen sebagai objek pemasaran. Marketing selain menyandang istilah dalam suatu teknik kerja bisnis untuk menghasilkan produk dan kualitas produk kepada pengguna juga menjadi acuan utama dalam penilaian suatu bisnis (Miftah, 2015). Mengenali kebutuhan konsumen sebagai target utama adanya timbal balik saling menguntungkan merupakan salah satu masalah 
esensial yang mutlak dipandang dalam memasarkan, untuk itu strategi pemasaran harus disesuaikan menurut kebutuhan konsumen saat ini (Ebitu, 2014) maupun kebutuhan strategi dalam menghadapi pesaing. Dalam kacamata Islam telah menyodorkan proses marketing yang bisa di terapkan secara adil tanpa mengecualikan target berupa keuntungan sebagai bagian sasaran marketing itu sendiri. Dimana distingtif marketing dalam pandangan Islam ialah yang melahirkan konsep rabbaniyah, akhlaqiyah, waqi'iyah, dan insaniyah (Hasan, 2014). Tujuan marketing yang hakiki dapat diraih, jika proses marketing diaplikasikan dengan mengfungsikan empat karakter tersebut. Segala bentuk bisnis dan negosiasi dalam syariah marketing menjelma suatu bakti kepada Allah SWT, jika menyertakan niat keikhlasan hanya untuk menggapai keridhaan illahi (Luntadjo, 2016). Bisnis yang mempunyai pengaruh, kelebihan dan kekhasan menggambarkan bisnis yang dominan sebagai buah dari akar spritual brand dari tujuan marketing yang berlandaskan prinsip Islam.

Saat ini pengaplikasian sebuah ilmu cenderung terlepas dari filosofi yang mendasari teori atas praktik ilmu (Scotland, 2012) seperti halnya dengan aplikasi praktik pola syariah marketing sering terlepas dari filosofi dasar ekonomi Islamnya. Selain itu juga konsep pemasaran Islam masih bergantung pada konsep pemasaran konvensional, dimana kajian konsep pemasaran Islam hanya digunakan sebagai alat pemasaran (Fathoni, 2018). Sehubungan dengan itu terminologi pemikiran ekonomi Islam oleh Imam al-Ghazali (Sirajuddin, 2016) sebagai salah-satu tokoh pemikir Islam merupakan peletak asas-asas kerangka ilmu maqasid alsyari 'ah menjelaskan bahwa misi dari ekonomi Islam adalah maslahat mewujudkan objek syara' (maqâshid as-syarî'ah) yang bermakna ijalb almanfa'ah wa daf' al-mafsadah (menarik kemanfaatan dan menolak kemudaratan) (Aminah, 2017). Terkait dengan itu pemasaran atau marketing sebagai bagian dari ekonomi Islam merupakan suatu bagian dari pembahasan yang terdapat dalam kitab-kitab karangan Al-
Ghazali yang digali dari Al-qur'an dan Hadits, untuk itu diperlukan suatu kajian mendalam mengenai konsep pemasaran yang sejalan dengan nilai-nilai mashlahat dalam maqashid syariah, sebagaimana pengaruh agama memainkan peran dalam menentukan strategi bisnis pola perilaku pemasaran harus memiliki filosofi dasar yang kuat guna mengendalikan rambu kebebasan berapresiasi dan berinovasi dalam bisnis (Sahlan, Abu-Hussin, \& Hehsan, 2018).

Manajemen pemasaran berlandaskan maqasid syariah adalah studi, program, pelaksanaan, prosedur dan penanganan proses yang dibangun dengan maksud mewujudkan, membentuk dan melindungi alterasi yang komersial dengan pasar target dengan implikasi untuk menyampaikan arah organisasi dengan memfokuskan kepada kadar syariah yang berlandaskan mashlahah, keseimbangan serta memprioritaskan adanya sikap kerelaan dan kasih sayang diantara penjual dan pembeli (Fauzi, 2017). Senada dengan itu studi orientasi pasar sering mengemukakan bahwa perusahaan perlu memonitor perubahan di pasar dan beradaptasi dengan kebutuhan pelanggan untuk meningkatkan kinerja perusahaan (Ghauri, Wang, Elg, \& Rosendo-Ríos, 2016), di samping itu juga dalam masalah evolusi pasar Al-Ghazali merumuskan pembangunan perkonomian bertolak kepada kaidah katauhidan, akhirat dan risalah. Tujuan ilmu ekonomi terbentuk dari prinsip tersebut yang tidak hanya mementingkan aspek material, akan tetapi lebih ditekankan kepada aspek ruhaniah (Yahanan, 2014). Tujuan penelitian ini adalah untuk menganalisis konsep marketing berbasis maqashid syariah Imam Alghazali yang dapat menjadi pegangan produsen dalam memasarkan kepada konsumen agar sejalan dengan nilai-nilai mashlahat. Penelitian ini difokuskan kepada perumusan konsep marketing yang berlandaskan kepada maqashid syariah menurut Imam Al-ghazali. 


\section{Metode Penelitian}

Jenis penelitian ini adalah kualitatif desktiptif dengan menggunakan pendekatan studi kepustakaan (Library Research). Studi kepustakaan menggambarkan analisis teoritis, kajian ilmiah, rujukan serta literatur yang berhubungan dengan kebiasaan masyarakat setempat, norma dan nilai yang terbangun pada kondisi lapangan yang diamati (Sugiyono, 2016). Dengan metode pengumpulan data dan fakta keterangan serta mendalami sumber-sumber yang termuat dalam jurnal dan makalah ilmiah, ensiklopedia, literatur, serta sumber data lain yang terkait dan relevan dengan topik, sehingga rumusan konsep marketing berbasis maqoshid syariah dapat terbentuk melalui teori-teori yang sudah ada sebelumnya.

\section{Hasil dan Pembahasan}

\subsection{Konsep Marketing}

Sebagai salah-satu kunci keberhasilan perusahaan marketing tidak saja mengupas doktrin bagaimana menjual suatu barang, dimana kepuasan konsumen perlu menjadi prioritas utama untuk menghasilkan keuntungan yang berkelanjutan. Pelayanan yang optimal kepada pelanggan sebagai target yang dipilih harus dibarengi dengan memiliki keungggulan produk/jasa dibandingkan dengan pesaing lain merupakan taktik untuk mencapai tujuan organisasional suatu perusahaan. Menurut (Kotler, Wong, Saunders, \& Armstrong, 2007), konsep pemasaran terdiri dari empat pilar :

a. Pasar Sasaran

Selektif dalam memilih pasar sebagai sasaran dari rancangan pemasaran dan program-program yang telah ditetapkan, merupakan kunci keberhasilan suatu perusahaan.

b. Kebutuhan Pelanggan

Upaya untuk menafsirkan kebutuhan pelanggan secara tepat menjadi penting, terutama sebagian pelanggan yang mempunyai kebutuhan yang tersembunyi dan tanpa disadari mereka sangat membutuhkannya. Pengategorian kebutuhan yang perlu mendapat perhatian diantaranya: kebutuhan yang jelas dan rill, kebutuhan yang sukar diketahui dan dipahami orang lain ataupun kebutuhan yang bersifat memenuhi hasrat kenyamanan.

c. Pemasaran Terpadu

Manakala seluruh departemen pada perusahaan saling membantu untuk memenuhi kebutuhan pelanggan hasilnya adalah pemasaran terpadu. Pemasaran terpadu dapat berlangsung di dua tingkatan. Pertama, beragam fungsi pemasaran (pelayanan pelanggan, riset pemasaran, manajemen produk, tenaga penjualan, periklanan) wajib bekerja sama. Kedua, pemasaran layak dirangkul oleh unit departemen lain dan bersama sama memperhatikan pelanggan.

d. Kemampuan Menghasilkan Laba

Misi dalam mendukung capaian suatu organisasi menjadi target akhir dari konsep pemasaran. Laba menjadi tujuan inti dari perusahaan swasta, sedangkan mempunyai pekerjaan dan cadangan dana pada organisasi kemasyarakatan atau nirlaba sudah cukup memadai menjadi tujuan utama. Mendapatkan keuntungan saja tidak seharusnya menjadi tujuan perusahaan, akan tetapi laba yang dihasilkan dari loyalitas pelanggan adalah suatu prestasi tersendiri. Mendapatkan profit melalui pelayanan yang baik kepada pelanggan menjadikan suatu perusahaan mempunyai nilai lebih dibanding pesaingnya.

\subsection{Maqoshid Syariah Imam Al-Ghazali}

Pemikiran sosio ekonomi Imam Al-Ghazali $\mathrm{Ra}$ bersumber dari suatu konsepsi yang dinamakan sebagai manfaat keselamatan secara islami kordial. Konsep maslahat menjadi tolak ukur seluruh kreasinya untuk mencapai kebaikan manusia yang kolektif, yakni melingkupi semua kegiatan perseorangan dalam kaitannya dengan masyarakat sekitarnya. Seorang ilmuwan muslim menyimpulkan bahwa Imam Al-Ghazali telah mendapatkan rancangan yang oleh para pakar kontemporer sebagai suatu pemikiran yang selalu dinantikan dan sukar ditentang (Zarqa, 1980). 
Imam Al-Ghazali Ra mengenalkan konsep masalih (utilitas, manfaat) maupun mafasid (disutilitas, kerusakan) dalam menyaring setiap masalah untuk menaikkan kemakmuran sosial (Sarif \& Ahmad, 2018). Selanjutnya, ia membatasi ukuran peranan kemasyarakatan dalam urutan tingkatan hajat individu dan sosial.

Maqashid syariah ialah sasaran-sasaran syariat dan hikmah terpendam dari diberlakukannya syariat hukum Allah (Soediro \& Meutia, 2018). Terwujudnya kemaslahatan manusia dan melenyapkan kemudaratan merupakan pokok dari tujuan syariah, sedangkan mengutamakan ajaran-ajaran dasar Islam seperti keadilan bersama dan kemerdekaan adalah mabadi (pokok dasar). Berdasarkan uraian di atas terdapat hubungan antara maqashid alsyari'ah (tujuan hukum Islam) dengan kemaslahatan (maslahat) (Khatib, 2018). Menurut Imam Al-Ghazali Ra, agama (al-dien), hidup atau jiwa (nafs), keluarga atau keturunan (nasl), harta atau kekayaan (maal), dan intelek atau akal ( $a q l)$ menjadi pedoman untuk menggapai kemaslahatan dan bergantung kepada eksplorasi dan konservasi dari lima (5) maslahah dasar tesebut. Kebaikan di dunia dan akhirat (maslahat al-din wa al-dunya) yang sejalan dengan ketentuan ajaran Islam menjadi penekanan dalam setiap pemikirannya (Abu Hamid Al-Ghazali, n.d.) Secara mendalam penjelasan 5 (Lima) mashlahah dasar tersebut diuraikan sebagai berikut:

a. Hifdz ad-din ( memelihara agama ) menjadi haq attadayyun (hak Beragama ) yaitu kewenangan untuk beribadah dan mempraktikkan perintah-perintah agama. Termasuk dalam hak ini ialah kebebasan dalam mendirikan sarana ibadah dan membangun pola relasi antar kelompok yang mempunyai keyakinan yang sama maupun berbeda keyakinan untuk menciptakan suasana kondusif dalam keberagaman

b. Hifdz an-nafs ( menjaga jiwa) menjadi haq alhayat ( hak hidup ). hak ini sepatutnya diarahkan untuk membangun nilai kehidupan yang berkualitas baik pribadi maupun dalam lingkup sosial masyarakat dan bukan sekedar sebagai sarana untuk pembelaan diri. Hak hidup perlu disesuaikan pada perbaikan kehidupan manusia secara keseluruhan, bukan bersifat fragmen

c. Hifdz al-aql ( memelihara akal),yaitu haq al-ta'lim ( hak mendapatkan pendidikan ). Menghormati akal bukan hanya berbatas kepada penjagaan kapabilitas akal untuk tidak termasuk mengidap gangguan jiwa atau hilangnya kesadaran. Orientasi pemeliharaan akal adalah pemenuhan untuk mendapatkan ilmu bagi setiap perseorangan dalam masyarakat. Perlindungan terhadap karya cipta, karya intelektual dan kreasi seseorang merupakan kategori proteksi terhadap akal.

d. Hifdz al-mal ( memelihara harta ), yaitu haq al-amal ( hak bekerja ). Hak ini tidak sekedar diartikan sebagai usaha untuk melindungi harta dari gangguan pihak lain. Hak ini juga bisa diartikan sebagai hak individu untuk memperoleh harta dengan jalan yang halal seperti bekerja. Dalam pengertian lebih luas, hak ini memberikan kekuasaan seseorang untuk menyediakan lapangan kerja bagi individu lain. Dengan demikian, setiap orang dapat menikmati hak kekayaan dalam kehidupannya agar meningkatkan kualitas kehidupan yang lebih baik

e. Hifdz al-irdl / Nasl ( memelihara kehormatan/ keluarga dan keturunan ) menjadi haq al-intirom al-insani ( hak atas kehormatan manusia ). Tidak hanya sekedar usaha untuk menjaga prestise diri serta keluarga dari tudingan dan gunjingan orang lain. Konservasi adaptasi dan adat budaya merupakan bidang terpenting dalam memelihara kehormatan dan status masyarakat. Dalam kerangka yang lebih umum, menjaga kehormatan dan martabat bangsa adalah termasuk dalam pembahasan hak membela kehormatan. 
Imam Al-Ghazali Ra membuat hierarki, yakni kebutuhan (daruriat), kesenangan atau kenyamanan (hajat), dan kemewahan (tahsinaat) dalam merumuskan bidang ekonomi dari fungsi kesejahteraan sosialnya. Hal tersebut sejalan dengan pemikiran filsuf yunani Aritoteles yang juga membagi kebutuhan menjadi beberapa tingkatan kategori seperti kebutuhan primer, kebutuhan sekunder dan kebutuhan tersier yang masuk sebagai kebutuhan akan barang mewah dan luks (Berthoud \& Lowry, 2006). Kebutuhan pokok manusia layaknya makanan, pakaian dan perumahan yang merupakan pengadaan pada level pertama menjadi pusat proteksi dari maslahat sebagai tujuan dasar, meskipun dalam pandangan Imam Al-Ghazali kebutuhankebutuhan tersebut mempunyai sifat elastis merujuk ruang dan waktu dan termasuk keinginan yang bersifat sosiopsikologis. Semua aktivitas dan kegiatan yang tidak terlalu mendesak sebagai kelompok kedua dan tetap menjadi hal yang dibutuhkan dalam meringankan serta memudahkan kehidupan manusia. Sedangkan kelompok ketiga meliputi kebutuhan pelengkap yang bersifat komprehensif, kesenangan dan masuk kategori fasilitas yang menghiasi hidup.

Meskipun demikian Imam Al-Ghazali tidak menghendaki dalam pencarian kebahagiaan akhirat sebagai tujuan akhir dengan meninggalkan tanggungan duniawi seseorang, terlebih dalam mencapai keselamatan dengan tetap terlibat dalam kegiatan dan aktivitas ekonomi pada umumnya adalah salah-satu upaya untuk meraih tujuan yang utama tersebut (Abu Hamid Al-Ghazali, n.d.). Dalam hal ini, Imam Al-Ghazali Ra mengutamakan sikap moderat dan kesahihan niat seseorang dalam setiap denyut ekonomi. Aktivitas ekonomi dapat bernilai ibadah jika dalam koridor dan tatanan aturan syar'i (Abu Hamid Al-Ghazali, n.d.). Lebih lanjut Imam Al-Ghazali memandang kewajiban sosial (fard al-kifayah) dalam meningkatkan pertumbuhan ekonomi merupakan bagian dari sunnatullah, yang apabila tidak terpenuhi kehidupan dunia akan rusak dan kemanusiaan akan terkikis (Abu Hamid Al-Ghazali, n.d.). Ia menekankan bahwa kegiatan ekonomi mutlak dilaksanakan secara efisien disebabkan bagian dari pemenuhan kewajiban agama seseorang (AlGhazali, n.d.). Kemudian, Ia menetapkan tiga argumentasi mengapa sesorang patut melakukan pekerjaaan dan aktivitas ekonomi, yaitu: pertama,untuk memenuhi kebutuhan hidupnya; kedua, untuk kemakmuran keluarga; dan ketiga, untuk menyantuni orang lain yang memerlukan bantuan. Menurutnya agama dapat menjadi objek yang perlu diperhatikan secara serius jika ketiga alasan tersebut tidak terpenuhi (Abu Hamid AlGhazali, n.d.). Imam Al-Ghazali Ra mempersoalkan mereka yang ikhtiarnya hanya sekedar terpaku untuk mencukupi kebutuhan hidupnya. Ia menyatakan

"Jika manusia masih tinggal pada tataran subsisten (sadd al ramaq) dan menjadi terlalu lemah, tingkat kematian akan bertambah, semua kegiatan dan keaktifan akan berhenti, dan masyarakat akan punah. Selanjutnya, agama akan runtuh, karena kehidupan dunia adalah ladang untuk beramal bagi kehidupan akhirat" (Abu Hamid Al-Ghazali, n.d.)

Walaupun Imam Al-Ghazali Ra memandang manusia senantiasa mengiginkan lebih (maximizers) dan melihat tabiat tersebut bukan sebagai sesuatu yang dilarang agama. Imam AlGhazali memahami keinginan manusia dalam menghimpun kekayaan untuk mempersiapkan kebutuhan di masa depan. Namun ia memperingatkan bahwa kecendurungan tersebut berpotensi mengarah kepada keserakahan dan pemuasan hawa nafsu pribadi. Dalam hal ini, ia memandang kekayaan sebagai ujian terbesar (Abu Hamid Al-Ghazali, n.d.) Lebih jauh, Imam Al-Ghazali Ra menyatakan bahwa penghasilan dan kekayaan didapatkan dari tiga sumber, yaitu usaha pribadi, keuntungan perniagaan dan pendapatan yang tidak terduga. Harta warisan, harta terpendam ataupun hadiah sebagai contoh dari sumber ketiga, Ia menegaskan bahwa sumber penghasilan tersebut mesti didapatkan secara benar dan tidak menyalahi aturan agama. Lebih lanjut Al-ghazali berpandangan serius 
terhadap keadilan yang dipaksakan terkait pendapatan dan kekayaan. Pendistribusian kekayaan yang berlandaskan etika agama harus lebih dikedepankan dibandingkan dengan kepentingan negara. Sesuatu menjadi lumrah apabila yang dapat menjadi penghalang dari tegaknya kekuasaan negara menjadi sasaran tindakan anarkis berupa pemaksaaan yang ditujukan kepada rakyat. Selain itu pengumpulan keuntungan serta pendistribusian dari penghasilan negara menjadi perhatian khusus dari Imam Al-Ghazali (Abu Hamid Al-Ghazali, n.d.). Imam Al-Ghazali $\mathrm{Ra}$ berpendapat sikap berlebih-lebihan dan pelit menjadi dua hal yang dipersalahkan akibat dari tidak adanya pembagian secara sukarela. Dampak dari itu berupa tindakan kejahatan dan penimbunan uang sehingga sirkulasi keuangan menjadi terhambat akibat dari ditekannya aspirasi masyarakat untuk berbuat dan memerankan fungsi sosial secara bebas (Abu Hamid Al-Ghazali, n.d.). Secara selintas kepada mereka yang berserah dan memutuskan untuk hidup berkekurangan serta tanpa adanya usaha untuk merubah keadaan tersebut dan menganggap hal tersebut merupakan ketentuan dari Allah SWT mendapat perhatian minim dari Imam Al-Ghazali (Abu Hamid Muhammad bin Muhammad al Ghazali, n.d.).

Berbagai konsep dan prinsip ekonomi yang secara detail di rumuskan kembali oleh pemikir baik di kalangan muslim maupun non- muslim, dimana digali dari pandangan secara umum mengenai teori sosioekonomi Imam Al-Ghazali. Sebagian besar permasalahan ekonomi dibahas dalam kitab Ihya Ulum al-Din yang secara garis besar mencakup permasalahan evolusi pasar dan uang, pertukaran sukarela, barter, peran negara dan keuangan publik serta aktivitas produksi.

\subsection{Konsep Marketing Berbasis Maqashid Syariah Imam Al-Ghazali}

Dalam kegiatan ekonomi, fokus pemasaran secara esensi terdapat tiga tahapan sekaligus aspek penting, yaitu: Pertama; tahapan dimana marketer mempersiapkan metode pemasarannya untuk tujuan memaksimalkan laba, Kedua; pelaksanaan dari rancangan yang telah disusun secara sistematis; Ketiga; proses evaluasi terhadap pola pemasaran yang telah dijalankan. Konsep maqasid yang telah dirumuskan oleh Imam Al-Ghazali diaplikasikan pada ketiga tahapan tersebut diatas. Maqasid syariah yakni, agama, jiwa, akal, keturunan, dan harta menjadi pedoman dasar bagi marketer, juga sebagai tolak ukur dalam mempertimbangkan efeknya bagi konsumen, sehingga tujuan untuk mendapatkan kemaslahatan secara bersama dapat terwujud

Dalam menawarkan dan memasarkan produk kepada konsumen seorang marketer perlu mempertimbangkan secara jujur dan penuh tanggung jawab bahwa produk tersebut tidak mengintervensi agama, jiwa, akal, keturunan, dan harta yang menjadi maslahah dasar manusia. Di sisi lain marketer perlu melakukan inovasiinovasi yang dapat memikat konsumen sebagai konsekuensi dari rasionalitas secara umum dari pola konsumen yang senantiasa memaksimumkan keinginan maupun keuntungan (maximer). Sebagaimana dibenarkan oleh Imam Al-Ghazali dalam kitab Ihya' Ulumudin mengungkapkan bahwa:

"Manusia gemar mengumpulkan harta dan kekayaan yang beraneka ragam. Bila ia telah mempunyai dua lembah emas, maka ia juga akan mengarapkan lembah emas yang ketiga". Kenapa? Karena "manusia memiliki ambisi yang tinggi, Ia kerap berasumsi bahwa kekayaan yang dimilki tidak cukup mungkin dapat bertahan, atau bisa jadi akan hancur sehingga ia makin akan membutuhkan lebih banyak. Ia berjuang untuk menyingkirkan ketakutan ini dengan menumpuk lebih banyak lagi. Namun ketakutan semacam ini tidak akan berhujung, bahkan sekiranya ia mempunyai semua harta di dunia" (Abu Hamid Al-Ghazali, n.d.)

Untuk mengatasi permasalahan di atas, marketer yang memiliki asumsi rasional dapat mengontrol melalui strategi drive market para konsumennya, sehingga konsumen dapat mengambil keputusan bijak dalam setiap aktivitas konsumsi atas produk/barang (konsumeris). Tujuan utama dari proses tersebut adalah kondisi dimana konsumen dapat 
mempertimbangkan terkait pemilihan skala memilah mana yang masuk kebutuhan dan mana proritas dalam memilih kebutuhan yang tidak memiliki mudharat lebih besar serta mampu keinginan.. Pola diagram asumsi rasionalitas ini dapat digambarkan sebagai berikut:

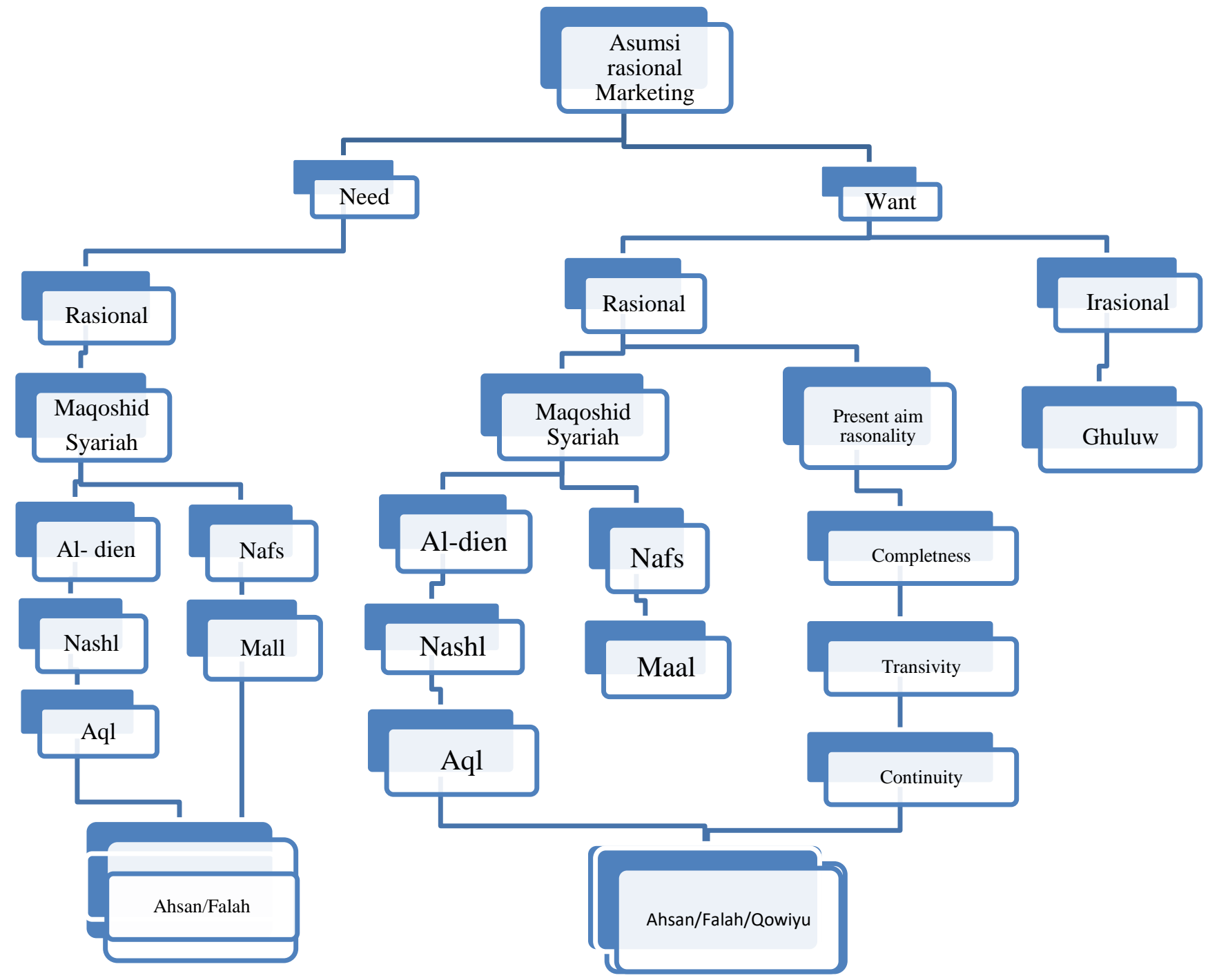

Gambar I. Diagram Asumsi Rasional Marketing

Berdasarkan diagram asumsi rasional diatas, marketer dalam upaya mengarahkan konsumen untuk selektif membedakan antara kebutuhan (need) dan keinginan (want). Spirit dari almaqashid asy-syari'ah menjadi pertimbangan seorang marketer dalam proses marketing dengan memperhatikan pola perilaku konsumsi dari konsumen. Dengan alasan estimasi tersebut konsumen dapat mengutamakan aspek kebutuhan dibanding aspek keinginan, seperti menentukan pembatasan kelas keperluan akan kebutuhan primer (dharuriyat), kemudian sekunder (hajjiyat) dan tersier (tahsiniyat). Untuk membawa manusia kepada maslahah divergensi rasionalitas Islam mempunyai ciri khusus dibanding dengan rasionalitas dalam ekonomi konvensional. Perbedaaan tersebut terdapat dalam dasar filosofi dan dimensi waktu yang melingkupinya. Konsep need (kebutuhan) daripada want (keinginan) dalam mencapai maslahah menjadi parameter, dimana need lebih dapat diukur daripada want. Sasaran dari pertimbangan tersebut konsumen lebih terdorong untuk menghindari kebutuhan yang bersifat madarat. Pola marketer dalam mengarahkan dan memperhatikan aspek kebutuhan dan keinginan yang rasional bagi konsumen dapat membawa pada perwujudan perilaku konsumsi yang lebih baik (ahsan) dan falah yakni keberhasilan kedepan yang berfaedah bagi dunia dan akhirat, sehingga penekanan aspek spritual menjadi pengutamaan, tanpa menepikan aspek material 
(Arif, 2018). Di sisi lain marketing yang diarahkan kepada konsumsi keinginan yang irasional (tidak berdasarkan akal/pikiran yang sehat) justru membawa kepada ghuluw (melampaui batas/berlebih lebihan) yang jelas tercela dan dilarang oleh syariat.

Pola pengenalan kebutuhan konsumen menjadi analisa dasar pola penyusunan produk atas asumsi rasional seorang pedagang atau produsen pemasaran yang menginginkan adanya timbal balik saling menguntungkan tentunya harus didasari oleh prinsip keadilan dan tanpa adanya penipuan (tadlis) dan ketidakjelasan (gharar). Inti dari konsep marketing dalam pemikiran al-Gazali dimana etika dan moral pelaku ekonomi dalam pasar mempunyai peranan yang sangat krusial. Secara khusus terkait konsep pemasaran dalam menghasilkan laba, Al-ghazali bahwa tujuan marketing untuk menghasilkan laba adalah hal yang fitrah bagi seorang produsen dengan syarat tidak menyampingkan akhirat sebagai tujuan dan dilakukan sesuai jalur syariat yang dibenarkan dalam agama, ia memperingatkan penguasaan profit dengan cara menimbun makanan dan komoditas dasar lainnya di saat terjadi kelangkaan merupakan tindakan eksploitasi secara zalim dan aktor yang terlibat menjadi terlaknat. Selain itu, al-Gazali bersikap sangat responsif terhadap margin yang eksesif. Laba akan menjadi berlebihan, untuk itu apabila harga yang ditawarkan pembeli lebih tinggi daripada harga yang ditetapkan di pasar maka pedagang selayaknya untuk menolaknya (Abu Hamid AlGhazali, n.d.). Beberapa pendapat Al-ghazali di atas sebagai bentuk dari perlindungan terhadap maslahah dasar manusia yang harus menjadi perhatian marketer dalam kegiatan bisnisnya. Penerapan konsep maslahah dalam marketing berdampak lebih luas kepada kesejahteraan yang merata (sosial) dan kemaslahatan bersama serta memelihara kesejahteraan, keadilan dan kestabilan ekonomi.

\section{Kesimpulan}

Dalam Pemikiran Imam Al-Ghazali Ra mengenai konsep kesejahteraanya, yang disinggung tentang lima tujuan syariat atau maqashid syariah, dapat dijadikan sebuah acuan para pelaku ekonom khususnya para marketer untuk dapat melakukan kegiatan proses bisnisnya sesuai aturan Allah SWT. Hal ini penting karena secara konsep mampu dijadikan rambu perjalan marketing para pebisnis. Dengan memperhatikan maqashid syariah dari awal perencanaan pemasaran, hingga pada taraf evaluasinya, marketer sebenarnya telah mampu melakukan pola pemasaran yang proposional, dan berkeadilan. Seperti halnya penerapan maqashid syariah yang mendorong marketer untuk tidak melakukan intervensi agama, tentunya akan tercermin pada penjualan produk yang halal saja, tidak ada unsur yang melanggar business ethic (riba, gharar, tadlis, maysir, dsb), bahkan tidak unsur intervensi ketauhidan maupun sosial.

\section{Ucapan Terimakasih}

Terima Kasih kepada Fakultas Ekonomi Universitas Negeri Gorontalo yang telah mendukung atas selesainya penelitian ini.

\section{Daftar Pustaka}

Abu Hamid Al-Ghazali. (n.d.). Ihya 'Ulum al-din, Juz 2. Beirut: Dar al-Nadwah.

Abu Hamid Muhammad bin Muhammad al Ghazali. (n.d.). al-Arba'in $f i$ Ushul al-Din. Lairo: Maktabah al-Tijariyah.

Al-Ghazali, A. H. (n.d.). Mizan al-Amal. Kairo: Dar al-Ma'arif.

Aminah, A. (2017). Maqasid Asy-Syari 'ah Pengertian Dan Penerapan Dalam Ekonomi Islam. Fitrah: Jurnal Kajian Ilmu-Ilmu Keislaman, 3(1), 167-184.

Arif, M. (2018). Filsafat ekonomi islam. Fakultas Ekonomi dan Bisnis Islam.

Berthoud, A., \& Lowry, S. T. (2006). The Archeology of Economic Ideas. The Classical Greek Tradition. Revue Économique, 220. https://doi.org/10.2307/3501782

Ebitu, E. T. (2014). Marketing strategies and consumers' satisfaction of cement products in Calabar, Nigeria. British Journal of Marketing Studies, 2(6), 52-67. 
Fathoni, M. (2018). Konsep Pemasaran Dalam Perspektif Hukum Islam. Jurisdictie (Vol. 9). https://doi.org/10.18860/j.v9i1.5135

Fauzi, Y. (2017). Manajemen Pemasaran Perpektif Maqasid Syariah. Jurnal Ilmiah Ekonomi Islam. https://doi.org/10.29040/jiei.v1i03.51

Ghauri, P., Wang, F., Elg, U., \& Rosendo-Ríos, V. (2016). Market driving strategies: Beyond localization. Journal of Business Research, 69(12), 5682-5693.

Hasan, D. B. N. (2014). Syariah Marketing. Dinar Jurnal Ekonomi Dan Keuangan Islam, 1(2).

Khatib, S. (2018). Konsep Maqashid Al-Syariah: Perbandingan Antara Pemikiran Al-Ghazali Dan Al-Syathibi. Jurnal Ilmiah Mizani: Wacana Hukum, Ekonomi Dan Keagamaan, 5(1).

Kotler, P., Wong, V., Saunders, J., \& Armstrong, G. (2007). Moderní marketing. Grada publishing as.

Luntadjo, M. M. (2016). Dasar Filosofi Marketing Syari'ah. Jurnal Ilmiah Al-Syir'ah, 7(1).

Miftah, A. (2015). Mengenal Marketing dan Marketers Syariah. Islamiconomic: Jurnal Ekonomi Islam, 6(2).

Sahlan, M. K., Abu-Hussin, M. F., \& Hehsan, A. (2018). Market coopetition: Implications of religious identity in creating value added partnership within halal mart retailers. Journal of Islamic Marketing. https://doi.org/10.1108/JIMA-04-2017-0046
Sarif, A., \& Ahmad, R. (2018). Konsep Maslahat dan Mafsadah menurut Imam al-Ghazali. TSAQAFAH. https://doi.org/10.21111/tsaqafah.v13i2.1183

Scotland, J. (2012). Exploring the Philosophical Underpinnings of Research: Relating Ontology and Epistemology to the Methodology and Methods of the Scientific, Interpretive, and Critical Research Paradigms. English Language Teaching, 5(9), 9-16.

Sirajuddin, S. (2016). Konsep Pemikiran Ekonomi Al-Ghazali. Laa Maisyir: Jurnal Ekonomi Islam, $3(1)$.

Soediro, A., \& Meutia, I. (2018). Maqasid Syariah As A Performance Framework Of Islamic Financial Institutuions. Jurnal Akuntansi Multiparadigma, 9(1).

Sugiyono. (2016). Memahami Penelitian Kualitatif. Bandung: Alfabeta.

Yahanan. (2014). Evolusi Pasar Menurut Pemikiran Imam Al-Ghazali. Hukum Islam.

Zarqa, A. (1980). Islamic economics: An approach to human welfare. In Studies in Islamic Economics: A Selection of Papers Presented to the First International Conference on Islamic Economics, held at Makka, under the auspices of King Abdul Aziz University, Jeddah. 